\title{
ALIMENTAÇÃO DE GIRINOS DE RÃ-TOURO COM DIFERENTES NÍVEIS DE PROTEÍNA BRUTA
}

\author{
José Teixeira de Seixas Filho ${ }^{1}$, Rodrigo Diana Navarro ${ }^{2}$, Lilian Nogueira da Silva ${ }^{1}$, \\ Luiza Nogueira DE SOUZA ${ }^{3}$ \\ 1 - Centro Universitário Augusto Motta (UNISUAM), Grupo AQÜISUAM, Laboratório de Pesquisa em Biologia - \\ seixasfilho@unisuam.edu.br \\ 2 - Faculdade de Agronomia e Veterinária da Universidade de Brasília \\ 3 - Centro Universitário Augusto Motta
}

\section{RESUMO}

Objetivou-se avaliar o desempenho de girinos da rã-touro alimentados com três níveis de proteína. Os girinos foram distribuídos em 12 caixas de polietileno $(62,5 \times 40 \times 16$ $\mathrm{cm})$, de coloração branca, com capacidade para 40L, as quais receberam $30 \mathrm{~L}$ de água, acondicionando 30 animais, com peso e comprimento médio de 0,027 \pm $0,009 \mathrm{~g}$ e $4,91 \pm 0,45 \mathrm{~mm}$, respectivamente, resultando em uma densidade de 1 girino por litro. Na alimentação dos girinos foram utilizadas rações comerciais com três níveis de proteína bruta (PB) $22 \%, 24 \%$ e $28 \%$, com granulometria de $0,5 \mathrm{~mm}$, administradas na proporção de $10 \%$ do peso dos girinos, distribuídas uma vez ao dia, às 12 horas. $\mathrm{O}$ delineamento experimental foi completamente casualizado com quatro repetições. Os parâmetros e a sobrevivência foram avaliados em cinco biometrias, em 60 dias. Não houve diferenças significativas $(\mathrm{P}>0,05)$ entre os parâmetros para os primeiros 15 dias. Desse período até o final do experimento, os animais apresentaram diferenças significativas $(\mathrm{P}<0,05)$ para peso, comprimento e consumo de ração, respectivamente, sendo que para todos, o melhor resultado foi dos que receberam ração com $28 \%$ PB $(5,279 \mathrm{~g}, 29,10 \mathrm{~mm}$ e $2,518 \mathrm{~g})$, seguidos pelos que receberam ração com $24 \% \mathrm{~PB}(3,558 \mathrm{~g}, 24,77 \mathrm{~mm}$ e $2,410 \mathrm{~g}$ ). A taxa de sobrevivência foi de $94,87 \%$ com ração de $22 \% \mathrm{~PB}$.

PALAVRAS-CHAVE: desempenho; girinos; proteína; rã-touro.

\section{BULLFROG TADPOLES FED WITH DIFFERENT LEVELS OF CRUDE PROTEIN}

This study aimed at evaluating the performance of bullfrog tadpoles fed three levels of protein. Tadpoles were divided into 12 white boxes of polyethylene $(62.5 \mathrm{x}$ $40 \times 16 \mathrm{~cm}$ ) with a $40 \mathrm{~L}$ capacity, which received $30 \mathrm{~L}$ of water, receiving 30 animals, with average weight and length of $0.027 \pm 0.009 \mathrm{~g}$ and $4.91 \pm 0.45 \mathrm{~mm}$, respectively, resulting in a density of 1 tadpole per liter. As for feeding, commercial diets were used with three levels of crude protein (CP), $22 \%, 24 \%$ and $28 \%$, with a
$0.5 \mathrm{~mm}$ diameter, administered at a rate of $10 \%$ of tadpoles weight distributed once a day at noon. The experimental design was completely randomized with four replications. The best percentage of survival, $94.87 \%$, was found in the $22 \%$ CP group. The other groups, with $24 \%$ and $28 \%$ protein, showed $81.17 \%$ and $86.50 \%$ of survival rate, respectively. These results showed that the rations were not sufficient to provide a complete performance to the animals. Similarities 
regarding crude protein were observed until the 15 th day among all the groups studied. However, there are some special physiological necessities, especially in relation to

KEYWORDS: frog culture; performance; protein; tadpoles.

\section{INTRODUÇÃO}

Os girinos representam a fase larvária dos anfíbios e seu ciclo de vida pode ser dividido em três fases: embrionária, larval e metamorfose. A fase embrionária constitui o período da fecundação e o desenvolvimento dentro do ovo, a fase larval iniciase com a eclosão do ovo e todo o período de desenvolvimento do girino, enquanto que a metamorfose se caracteriza pelo momento em que ocorrem as mudanças do girino para o anfíbio adulto (ALTIG \& MCDIARMID, 1999).

A fase de girinagem é um ponto de estrangulamento da ranicultura, devido às alterações na continuidade da produção, por doenças e mortalidades em massa, ocasionadas por procedimentos zootécnicos executados de forma empírica, principalmente a administração de alimentos inadequados, uma vez que pouco se conhece sobre as exigências nutricionais das rãs, o que proporcionaria melhores desempenhos aos animais (SEIXAS-FILHO et al., 1998a; SEIXAS-FILHO et al., 1998b).

O desenvolvimento eficiente e saudável dos animais passa obrigatoriamente pelo fornecimento de uma dieta que satisfaça as necessidades básicas de crescimento, contendo concentrações próximas do ideal em seus diversos componentes, aliados à tecnologia de preparação. A estocagem, a concentração de macro e micronutriente e a biodisponibilidade dos nutrientes são exemplos de parâmetros que interferem no desenvolvimento do animal (NAVARRO et al., 2007).

As rações utilizadas na alimentação de girinos têm como principal fonte de proteína de origem animal a farinha de peixe, a qual tem apresentado, normalmente, baixa qualidade nutricional, com produção sazonal e alto custo, elevando, portanto, o custo de produção do ranicultor (ALBINATI et al., 2000). LIMA \& AGOSTINHO (1992) relataram que o custo com alimentação de rãs representa $57 \%$ do custo total da criação.

BARBOSA et al. (2005) concordam que a alimentação de girinos em sistema de criação comercial é de fundamental importância, não só em termos de quantidade, como de qualidade; porém, the protein intake, that were not well fulfilled despite the animals'good performance showed in this period.

os autores mencionaram que os trabalhos encontrados na literatura acerca de níveis nutricionais e suas relações com o crescimento são escassos. Os mesmos autores observaram que girinos alimentados com dietas com alto teor de PB $(46,5 \%)$ apresentaram melhor desempenho e crescimento heterogêneo mais elevado, e que níveis protéicos entre 26,6 e $33,6 \%$ são adequados ao desenvolvimento dos girinos.

No Brasil, principalmente no Rio de Janeiro, o mercado para carne de rã ainda é pequeno, mas estabilizado, sendo que a totalidade dos seus ranicultores produz seus próprios girinos e cerca de $21 \%$ eventualmente os comercializam com outros produtores (SEBRAE, 2002).

Nesse sentido, objetivou-se com este estudo avaliar o desempenho de girinos da rã-touro alimentados com diferentes níveis de proteína.

\section{MATERIAL E MÉTODOS}

O experimento foi conduzido no Laboratório de Pesquisas em Biologia do Curso de Licenciatura em Ciências Biológicas da UNISUAM - Rio de Janeiro - RJ, com duração de 60 dias. Foram utilizados 360 girinos de rã-touro (Lithobates catesbeianus) com 15 dias, no estágio 25 de GOSNER (1960), provenientes de uma mesma desova, com peso e comprimento médio de $0,027 \pm 0,009 \mathrm{~g}$ e $4,91 \pm 0,45 \mathrm{~mm}$, respectivamente.

Os girinos foram distribuídos em 12 caixas de polietileno $(62,5 \times 40 \times 16 \mathrm{~cm})$, de coloração branca com capacidade para $40 \mathrm{~L}$, e abastecimento individual, as quais receberam 30L de água, acondicionando 30 animais, resultando em uma densidade de um girino por litro, segundo ARRUDA SOARES et al. (1985).

A água foi mantida a uma temperatura constante de $25^{\circ} \mathrm{C}\left( \pm 1^{\circ} \mathrm{C}\right)$ e sua renovação foi de aproximadamente $200 \%$ do volume a cada 24 horas. O nível de água no interior das caixas foi mantido por meio de dispositivo tipo "joelho" adaptado na lateral das caixas, segundo SEIXAS-FILHO et al. (1997), permitindo que a água fosse escoada por meio de canaletas de PVC acondicionadas lateralmente às bancadas e conectadas em esgoto (Figura 1). 


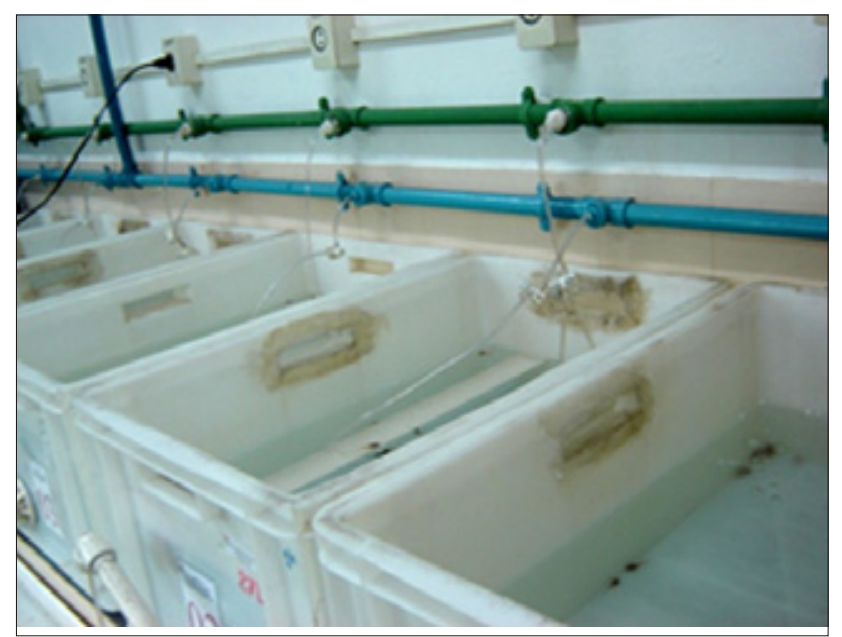

Figura 1 - Posicionamento, escoamento e abastecimentos da água e do ar, dos módulos experimentais para girinos de rã-touro.

Cada módulo experimental recebeu aeração constante, por meio de soprador e mangueiras plásticas 3/16', providas de pedras porosas em suas extremidades e reguladas por registro de mesmo calibre.

Para alimentação dos girinos foram utilizadas três rações comerciais com diferentes níveis de proteína bruta $(22 \%, 24 \%$ e $28 \%$ de PB) (Tabela 1$)$, com granulometria de $0,5 \mathrm{~mm}$, administradas diariamente na proporção de $10 \%$ do peso dos girinos,uma vez ao dia, às 12 horas, de acordo com SEIXAS-FILHO et al. (1998a).

Tabela 1 - Composição das rações comerciais com $22 \%, 24 \%$, e $28 \%$ de proteína bruta utilizadas na alimentação de girinos de rã-touro

\begin{tabular}{lccc}
\hline Niveis de garantia & \multicolumn{3}{c}{ Raçöes } \\
\hline Umidade máxima & $22 \%^{1}$ & $24 \%^{2}$ & $28 \%^{3}$ \\
Proteina bruta (PB) & 13 & 13 & 13 \\
Estrato etéreo (mínimo) & 22 & 24 & 28 \\
Matéria fibrosa (máximo) & 4 & 4 & 4 \\
Cinzas (máximo) & 10 & 10 & 10 \\
Cálcio-Ca (máximo) & 14 & 14 & 14 \\
Fósforo-P (mínimo) & 3 & 2,5 & 3 \\
\hline Cón & 1 & 1 & 0,6 \\
\hline
\end{tabular}

\section{Composição Básica}

Farelo de soja, farinha de peixe, farelo de trigo, farelo de glúten de milho $60 \%$, farinha de carne e osso, milho, farinha de sangue, óleo de peixe, carbonato de cálcio, fosfato bicálcico, sal suplemento, vitamina.1, mineral2 e antioxidante3.

1 Composição por Kg: VIT. A-12000 UI, VIT. D3-4000 UI, VIT. E-150 UI, VIT. K-10 UI, Ac.Fólico-10mg, Biotina-0,8 mg, Colina$500 \mathrm{mg}$, Niacina-150 mg, Pantotenato de Cálcio-50mg, Tiamina-30 mg, Riboflavina-30 mg, Piridoxina B6-30 mg, VIT.B12-35 $\mu \mathrm{g}$, VIT.C-300 mg. 2 Composição por Kg: Mg-700 mg, Mn -30 mg, Zn-200 mg, Cu-15 mg, Fe-100 mg, I-1 mg, Se-0,3 mg. 3Etoxiquina $-250 \mathrm{mg}$

A ração fornecida aos girinos foi acondicionada em cochos que consistiam em tubos PVC de $50 \mathrm{~mm}$, cortados no sentido do comprimento, com extensão igual à largura da caixa. Os cochos foram fixados nas laterais do módulo experimental, para que permanecessem sem movimento (Figura 2).

A limpeza das caixas foi realizada todos os dias por sifonagem de fundo, retirando-se as fezes e os restos alimentares. Diariamente, pela manhã e à tarde, foram tomadas as temperaturas do ar e da água por meio de termômetro de coluna de mercúrio, com escala em centígrados, de 0 a $60^{\circ} \mathrm{C}$. O controle da amônia e do $\mathrm{pH}$ foi efetuado diariamente, por meio de colorimetria, com auxílio de kit comercial.

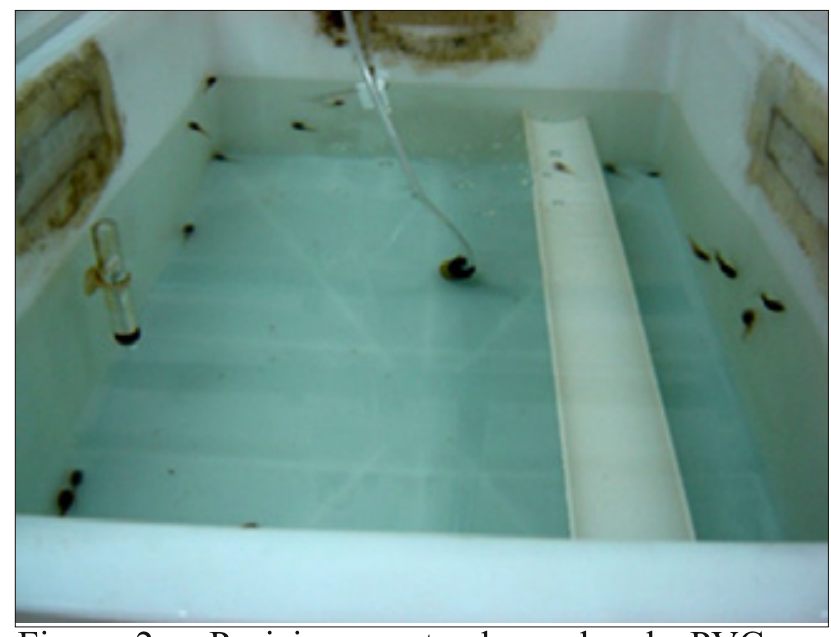

Figura 2 - Posicionamento do cocho de PVC no módulo experimental para alimentação dos girinos de rã-touro. 
As biometrias foram realizadas quinzenalmente, avaliando-se o peso, o comprimento e a sobrevivência. Os girinos foram colocados sobre toalha de pano umedecida, para retirada do excesso de água, sem que houvesse desidratação abrupta e mensurados da boca até a inserção da cauda, com auxílio de paquímetro digital, com precisão de centésimos de milímetro. Em seguida, cada animal foi transferido para recipiente plástico com volume de aproximadamente $5 \mathrm{~mL}$ de água e pesado em balança analítica, previamente tarada, com precisão de $0,001 \mathrm{~g}$.

Para avaliação do consumo (CO), a sobra da ração administrada aos animais foi retirada dos cochos a cada 24 horas, por sifonagem, com auxílio de mangueira com diâmetro de 3/16' e filtragem, por meio de filtro com malha de $0,5 \mathrm{~mm}$, sem contaminação com as fezes. As sobras foram secas em estufa ventilada a $55^{\circ} \mathrm{C}$, durante 24 horas. Após sua retirada da estufa, foram deixadas durante uma hora para entrar em equilíbrio com o meio ambiente e pesadas em balança digital com precisão de $0,001 \mathrm{~g}$. O consumo foi então obtido pela diferença entre a quantidade oferecida e a sobra de ração.

A conversão alimentar aparente (CAA) foi obtida pela razão entre o consumo de ração $(\mathrm{CO})$ e o ganho de peso (GP). Por sua vez, o ganho de peso foi obtido pela diferença entre os pesos de duas biometrias consecutivas.

O delineamento experimental utilizado foi inteiramente ao acaso, no esquema em parcela subdividida, com quatro repetições. Nas parcelas foram testados os teores de proteína bruta das rações co- merciais $(22,24$ e $28 \%$ PB). As subparcelas foram constituídas por cinco biometrias: na instalação do experimento ( 0 dia) e aos 15, 30, 45 e 60 dias após a instalação.

Os dados de peso (g), de ganho de peso (g), do consumo de ração (g), da conversão alimentar aparente e do comprimento $(\mathrm{mm})$ foram submetidos à análise de variância e teste $\mathrm{F}$. Os teores de proteína bruta foram comparados por meio do teste de Newman-Keuls a $5 \%$ de probabilidade.

\section{RESULTADOS E DISCUSSÃO}

A temperatura do ar apresentou média das máximas e mínimas de 30 e $25^{\circ} \mathrm{C}$, respectivamente. A média da temperatura da água variou de 24 a $26^{\circ} \mathrm{C}$. O pH manteve-se na faixa de 7,0 a 8,9 . Os valores de temperatura e $\mathrm{pH}$ encontraram-se dentro dos limites aceitáveis para os girinos, sendo semelhantes aos das condições dos trabalhos de FONTANELLO et al. (1982); SEIXAS-FILHO et al. (1998a); SEIXAS-FILHO et al. (1998b), concordando com SIPAÚBA-TAVARES (1994) que ressaltou que a boa qualidade da água em tanques e viveiros é a chave do sucesso da produção racional da aquicultura.

Não foi observada diferença significativa entre as rações testadas. Esse fato diverge dos resultados observados por BARBOSA et al. (2005), que observaram que a ração com $22,5 \%$ de $\mathrm{PB}$ provocou cerca de $50 \%$ de mortalidade dos animais após 45 dias de experimentação.

Tabela 2 - Sobrevivência e peso médio de girinos de rã-touro alimentados com rações comerciais com diferentes teores de proteína bruta (PB)

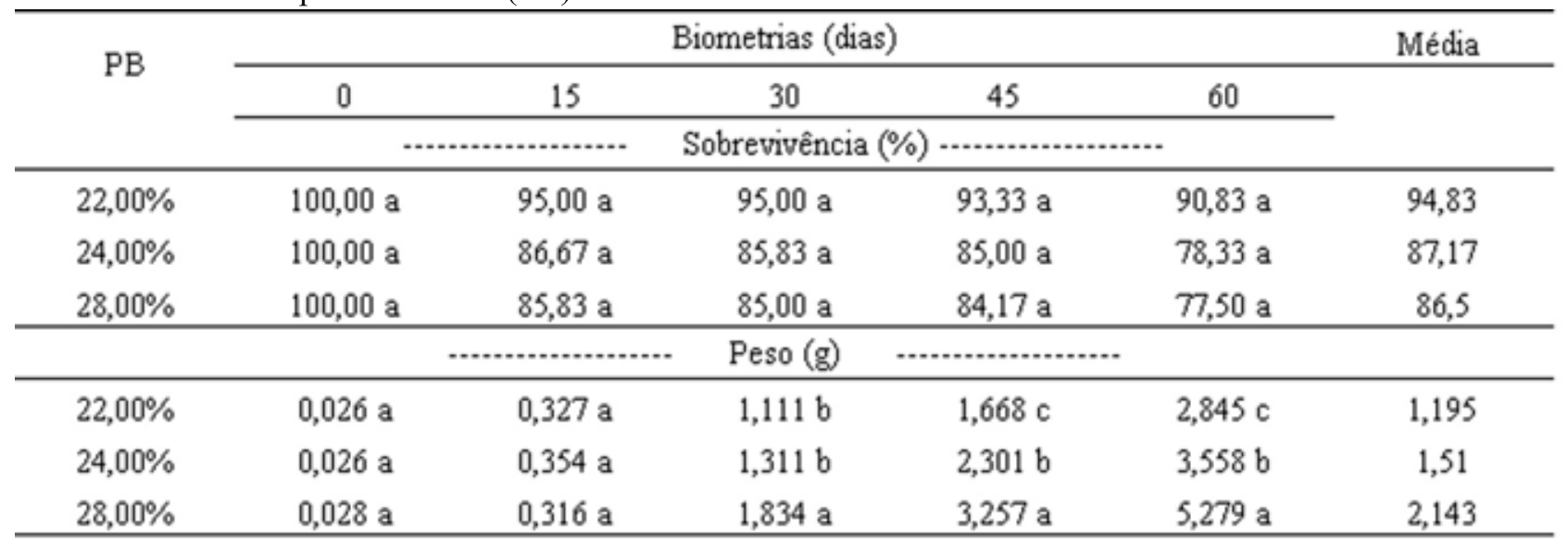

Em cada biometria (coluna), médias seguidas de pelo menos uma mesma letra não diferem entre si pelo teste de Newman-Keuls $(\mathrm{P}>0,05)$.

Apesar de a sobrevivência dos animais alimentados com ração com $22 \%$ de PB ter sido alta, seu peso médio ao final do experimento foi o menor $(2,845 \mathrm{~g})$ entre os teores de PB testados. 
O melhor desempenho em peso médio foi observado nos girinos alimentados com a ração com $28 \%$ de $\operatorname{PB}(5,279 \mathrm{~g})$, seguido da ração com $24 \%$ (3,558 g). Comportamento semelhante foi observado por CARMONA-OSALDE et al. (1996) e HAYASHI et al. (2004).

Vale ressaltar que, até 15 dias, não houve diferença significativa $(\mathrm{P}>0,05)$ no peso dos girinos. Esse fato indica que, até essa data, os girinos podem ser alimentados com qualquer uma das três rações $(22,24$ ou 28\% PB), sem que haja interferência em seu peso médio. Supõe-se que existam limitações fisiológicas nesse período que interferem na utilização dos nutrientes das rações testadas, uma vez que SEIXAS-FILHO et al. (2006a), avaliando histologicamente o trato gastrintestinal de girinos de rã-touro alimentados com diferentes níveis de proteína bruta na ração, observaram a formação completa do pâncreas e do fígado cerca de 25 dias após o início da alimentação exógena.

Durante todo o período experimental, não foi observada diferença significativa para consumo de ração (Tabela 3).

$\mathrm{Na}$ maioria das biometrias, a conversão alimentar aparente não apresentou diferenças significativas $(\mathrm{P}>0,05)$ entre as rações estudadas. No último período, a CAA média observada foi 2,$84 ; 3,20$ e 1,68 , para os girinos alimentados com $22 \%, 24 \%$ e $28 \%$ de $\mathrm{PB}$, respectivamente. A conversão obtida com $28 \%$ de PB foi próxima aos resultados encontrados por SECCO et al. (2002) que substituíram a farinha de peixe pela silagem de peixe na alimentação de girinos de rã-touro e obtiveram CAA entre 1,04 e 1,48 .

Tabela 3 - Ganho de peso, consumo de ração e conversão alimentar aparente média de girinos de rã-touro alimentados com rações comerciais com diferentes teores de proteína bruta (PB).

\begin{tabular}{|c|c|c|c|c|c|}
\hline \multirow[t]{2}{*}{$\mathrm{PB}$} & \multicolumn{4}{|c|}{ Periodos (dias) } & \multirow[t]{2}{*}{ Médias } \\
\hline & $0-15$ & $15-30$ & $30-45$ & $45-60$ & \\
\hline & \multicolumn{3}{|c|}{ Ganho de peso $(\mathrm{g})$} & \multicolumn{2}{|l|}{ 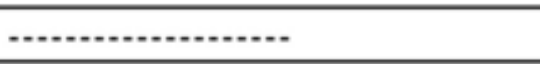 } \\
\hline $22,00 \%$ & $0,300 \mathrm{a}$ & $0,784 \mathrm{~b}$ & $0,536 \mathrm{c}$ & $1,125 \mathrm{~b}$ & 0,686 \\
\hline $24,00 \%$ & 0,324 a & $0,954 \mathrm{~b}$ & $0,977 \mathrm{~b}$ & $0,977 \mathrm{~b}$ & 0,808 \\
\hline \multirow{2}{*}{$28,00 \%$} & $0,283 \mathrm{a}$ & $1,516 \mathrm{a}$ & $1,404 \mathrm{a}$ & 1,755 a & 1,24 \\
\hline & 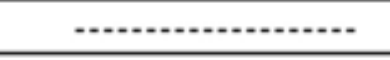 & \multicolumn{2}{|c|}{ Consumo de ração (g) } & (n......................... & \\
\hline $22,00 \%$ & $1,839 \mathrm{a}$ & $1,952 \mathrm{a}$ & $2,109 \mathrm{a}$ & $2,331 \mathrm{a}$ & $2,058 \mathrm{~b}$ \\
\hline $24,00 \%$ & $2,130 \mathrm{a}$ & $2,179 \mathrm{a}$ & 2,524 a & 2,805 a & $2,410 \mathrm{a}$ \\
\hline \multirow[t]{2}{*}{$28,00 \%$} & 2,252 a & $2,247 \mathrm{a}$ & $2,655 \mathrm{a}$ & $2,916 \mathrm{a}$ & $2,518 \mathrm{a}$ \\
\hline & 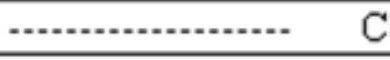 & \multicolumn{2}{|c|}{ Conversão alimentar aparente } & (.................... & \\
\hline $22,00 \%$ & $6,13 \mathrm{a}$ & $2,52 \mathrm{a}$ & $5,10 \mathrm{a}$ & $2,84 \mathrm{a}$ & 4,15 \\
\hline $24,00 \%$ & $6,80 \mathrm{a}$ & 2,31 a & $2,63 \mathrm{~b}$ & $3,20 \mathrm{a}$ & 3,74 \\
\hline $28,00 \%$ & $8,17 \mathrm{a}$ & $1,53 \mathrm{a}$ & $1,93 \mathrm{~b}$ & $1,68 \mathrm{a}$ & 3,33 \\
\hline
\end{tabular}

Em cada período (coluna), médias seguidas de pelo menos uma mesma letra não diferem entre si pelo teste de Newman-Keuls $(\mathrm{P}>0,05)$.

$\mathrm{O}$ comprimento dos girinos não apresentou diferenças significativas $(\mathrm{P}>0,05)$ entre os teores de PB estudados nos primeiros 15 dias de experimentação (Tabela 4). $\mathrm{O}$ fato de não haver diferença significativa para peso final refletiu no crescimento do girino (Tabelas 2 e 4 ).

A partir do $15^{\circ}$ dia até o final do experimento ocorreram diferenças significativas no comprimento médio $(\mathrm{P}<0,05)$, sendo que girinos alimentados com a ração contendo $28 \%$ de $\mathrm{PB}(29,1 \mathrm{~mm})$ apresenta- ram o maior comprimento, seguido pela ração com $24 \%$ de PB $(24,77 \mathrm{~mm})$, cujo comprimento se igualou àquele dos animais alimentados com $22 \%$ de $\mathrm{PB}$ $(24,28 \mathrm{~mm})$.

Nas fases iniciais os girinos utilizam melhor os carboidratos do que os lipídeos e proteínas e também apresentam maior atividade enzimática da enzima amilase, o que sugere que, nesta fase, é possível o uso de ração com menor teor de lipídeos e proteínas (LEONE et al., 1976). 
Tabela 4 - Comprimento médio de girinos de rã-touro alimentados com rações comerciais com diferentes teores de proteína bruta $(\mathrm{PB})$.

\begin{tabular}{|c|c|c|c|c|c|c|}
\hline \multirow{2}{*}{$\mathrm{PB}$} & \multicolumn{5}{|c|}{ Biometrias (dias) } & \multirow{2}{*}{ Média } \\
\hline & 0 & 15 & 30 & 45 & 60 & \\
\hline & (........ & (....... & Comprimento (mm) & $\ldots . .$. & (n)........ & \\
\hline $22,00 \%$ & 5,00 a & 11,05 a & $16,29 \mathrm{~b}$ & $19,42 \mathrm{C}$ & $24,28 \mathrm{~b}$ & 15,21 \\
\hline $24,00 \%$ & 4,93 a & 10,88 a & $17,17 \mathrm{~b}$ & $22,47 \mathrm{~b}$ & $24,77 \mathrm{~b}$ & 16,04 \\
\hline $28,00 \%$ & $4,80 \mathrm{a}$ & $10,83 \mathrm{a}$ & 18,70 a & 25,12 a & 29,10 a & 17,71 \\
\hline
\end{tabular}

Em cada biometria (coluna), médias seguidas de pelo menos uma mesma letra não diferem entre si pelo teste de Newman-Keuls $(\mathrm{P}>0,05)$.

No presente estudo, até aos 15 dias de experimentação o peso e o comprimento dos girinos não foram afetados pelos teores de proteína bruta das rações, indicando que nesse período os girinos não se mostraram eficientes em aproveitar a proteína disponível, independente do nível utilizado. É necessário o aprimoramento das técnicas de formulação de ração para girinos para que se obtenha o maior número de rãs-touro adultas de boa qualidade. Essas informações poderão nortear novos experimentos, melhorar as condições de cultivo, valorizar a atividade no sentido econômico, assim como fornecer embasamento à nutrição e manejo desses animais em cativeiro.

\section{CONCLUSÃO}

A ração com $28 \%$ de proteína bruta, nestas condições experimentais, mostrou-se mais adequada ao desenvolvimento dos animais.

\section{REFERÊNCIAS}

ALBINATI, R. C. B.; LIMA, S. L.; TAFURI, M. L.; DONZELE, J. L. Digestibilidade aparente de dois alimentos protéicos e três energéticos para girinos de rãtouro (Rana catesbeiana Shaw, 1802). Revista Brasileira de Zootecnia, v.29, n.6., p.2151-2156, 2000.

ALTIG, R.; MCDIARMID, R. W. Body plan: developmental and morphology. In: Tadpoles: The Biology of Anuran larvae. Ed. MCDIARMID, R. W. and R. ALTIG. Chicago Press, Chicago, 1999, p.24-51.

ARRUDA SOARES, H.; FONTANELLO, D.; MANDELLI JÚNIOR, J. Efeito da densidade de população no ganho de peso de girinos de rã-touro (Rana catesbeiana Shaw, 1802). Boletim do Instituto de Pesca de São Paulo, v.10, p.47-51, 1985.

BARbOSA, J. M.; SILVEIRA, A. M. GOMIDE, C. A. Crescimento heterogêneo de girinos de rã-touro alimentados com diferentes rações. Pesquisa Agropecuária Brasileira, v. 40, n.10, p 1015-1019, 2005.

CARMONA-OSALDE, C.; OLIVERA-NOVOA, M.A.; RODRÍGUEZ-SERNA, M.; FLORES-NAVA, A. Estimation of the protein requirement for bullfrog (Rana catesbeiana) tadpoles, and its effect on metamorphosis ratio. Aquaculture, v.141, p.223-231, 1996.

FONTANELLO, D; ARRUDA SOARES, H.; MANDELLI JR., J.; REIS, J. M. Crescimento de girinos de Rana catesbeiana, SHAW, 1802 (rã-touro) criadas com rações de diferentes níveis protéicos. Boletim do Instituto de Pesca, v.9 (único), p.125-129, 1982.

GOSNER, K.L. A simplified table for staging anuran embryos and larvae with notes on identification. Herpetologica, v.16, p.183-190, 1960.

HAYASHI, C.; SOARES, C.M.; GALDIOLI, E.M.; FURUYA, V.R.B.; BOSCOLO, W.R. Desenvolvimento de girinos de rã-touro (Rana catesbeiana Shaw, 1802) cultivados em diferentes densidades de estocagem em tanques-rede. Revista Brasileira de Zootecnia, v.23, n.1, p.14-20, 2004.

LIMA, S.L.; AGOSTINHO, C.A. A Tecnologia de criação de rãs. Viçosa-MG: UFV, 1992. 168p.

NAVARRO, R.D., LANNA, E. A. T., DONZELE, J. L., MATTA, S.L.P, SOUZA, M. A. Níveis de energia digestível da dieta sobre o desempenho de piauçu (Leporinus macrocephalus) em fase pós-larval. Acta Scientiarum Animal Science, v. 29, n.1:109-114. 2007.

SECCO, E. M.; STÉFANI, M. V.; VIDOTTI, R. M. Substituição da farinha de peixe pela silagem de peixe na alimentação de girinos de rã-touro (Rana catesbeiana). Ciência Rural, v.32, n. 3, p.505-509, 2002.

SEIXAS-FILHO， J.T.; MELLO， S.C.R.P.; SILVA, J.M.F.; TOMAS, J.E.; MELO, C.M.S. Efeito dos níveis 
de energia e proteína bruta no desempenho de girinos (Rana catesbeiana Shaw, 1802). Revista Brasileira de Zootecnia, v.27, p.664-669, 1998b.

SEIXAS-FILHO, J.T.; MELLO, S.C.R.P.; VEIGA, R.C.A.; MIRANDA, R.G.B.; SANTOS, C.A.N. Efeito da granulometria da ração sobre o desempenho de girinos de Rana catesbeiana. Revista Brasileira de Zootecnia, v.27, p.224-230, 1998a.

SIPAÚBA-TAVARES, L.H.S. Limnologia aplicada à aquicultura. Jaboticabal: FUNEP, 1994. 70p.

Protocolado em: 02 nov. 2009. Aceito em: 18 mar. 2011. 